\title{
Correction to: The Resonance of Resonance: Critical Theory as a Sociology of World-Relations?
}

\author{
Simon Susen ${ }^{1}$ \\ Published online: 11 May 2019 \\ (C) Springer Science+Business Media, LLC, part of Springer Nature 2019
}

\section{Correction to: International Journal of Politics, Culture, and Society https://doi.org/10.1007/s10767-019-9313-6}

The previous version of this article, which was made available without the author's permission, contained several minor errors. These errors have been corrected and, therefore, do not appear in the revised version of the article.

Publisher's Note Springer Nature remains neutral with regard to jurisdictional claims in published maps and institutional affiliations.

The online version of the original article can be found at https://oi.org/10.1007/s10767-019-9313-6

Simon Susen

Simon.Susen@ city.ac.uk; http://www.city.ac.uk/people/academics/simon-susen

1 Department of Sociology, School of Arts and Social Sciences, City, University of London, Northampton Square, London EC1V 0HB, UK 